\title{
Uma Análise da Variação Lexical na Galícia e na Bahia: denominações para 'calvo'
}

A Lexical Analysis in GaLiCia and in Bahia: Designations For 'BALD’

Cezar Alexandre Neri Santos*

Marcela Moura Torres Paim**

Resumo: Este trabalho insere-se na perspectiva de investigação lexical, constituindo uma análise da variação semântico-lexical nas áreas galega e baiana e traz como benefício mais latente a comparação de dados em português brasileiro e em galego, línguas cognatas no âmbito da genealogia linguística. Assim, no que concerne à Galícia, será analisado o Atlas Lingüístico Galego (BLANCO; GARCIA; FERNÁNDEZ, 2005) e, no que diz respeito ao Brasil, serão analisados os dados da Bahia, registrados no Atlas Lingüístico de Sergipe (FERREIRA et al., 1987). Objetiva-se examinar as realizações linguísticas para 'calvo' em dois vieses: (i) semântico, dispõe as raízes motivadoras para a formação do nome no plano paradigmático da língua, entendendo a seleção linguística como um ato político-cultural; (ii) lexicográfico, verifica a dicionarização, ou não, das formas inscritas na carta, por meio de dicionários históricos, etimológicos e de língua latina, bem como se tais marcações lexicográficas apresentam significados referentes à calvície. Pretende-se, então, nos atlas em questão, verificar o tipo de relação que se pode estabelecer entre os léxicos galego e baiano quanto às denominações que preenchem o conceito selecionado.

Palavras-chave: Calvo. Bahia. Galícia.

* Mestrado em Letras pela Universidade Federal de Sergipe (2012). Professor Assistente II da Universidade Federal de Alagoas. Contato: cezarneri@hotmail.com.

** Doutorado em Letras e Linguística pela Universidade Federal da Bahia (2007). Professor Adjunto IV da Universidade Federal da Bahia. Contato: marcelamtpaim@yahoo.com.br. 
Abstract: This paper is part of a lexical research, providing an analysis of the semantic-lexical variation in Galician and Bahia areas and has as more latent benefit the comparison of data in Brazilian Portuguese and Galician, cognate languages within the linguistic genealogy. Thus, with regard to Galicia territory, the Atlas Lingüistico Galego will be analyzed (BLANCO; GARCIA; FERNÁNDEZ, 2005) and, with regard to Brazil, data from Bahia will be analyzed, recorded in Atlas Lingüistico de Sergipe (FERREIRA et al., 1987). The objective is to examine the linguistic designations for 'bald' in two biases: i) semantic, providing the motive roots of name formation in the paradigmatic plane of language, understanding the language selection as a political-cultural act; ii) lexicographical, checking whether these names are and how they are on historical and etymological, Portuguese and Latin Language dictionaries or not, as well as whether such lexicographical markings have meanings related to baldness. Through these Atlas it is intended to check the type of relationship that can be established between the lexicon for 'bald' in Galicia and in Bahia. Keywords: Bald. Bahia. Galicia.

\section{Introdução}

Comparar é um ato humano universal e o léxico de uma língua é, dentre todos os níveis linguísticos, o que, de maneira mais concreta, permite representar, mi(s)tificar, identificar valores assumidos por um povo por meio da seleção de seus usos linguísticos. Neste artigo, por meio do cotejo do corpus constituído a partir dos dados da carta 80 do Atlas Lingüistico de Sergipe (FERREIRA et al., 1987), doravante ALS, que está no conjunto das cartas BA-SE (Bahia-Sergipe), e da carta 99 do Atlas Lingüístico Galego (BLANCO; GARCIA; FERNÁNDEZ, 2005), doravante ALGa, que tratam das acepções para 'calvo', espera-se demonstrar como esses traços, historicamente construídos, admitem a percepção de uma interdependência entre léxico e cultura, uma vez que o ato de nomeação ocorre em comunidades linguísticas ativas, entrecortadas por elementos extralinguísticos.

O léxico é a representação das mudanças sócio-históricas pelas quais determinada comunidade linguística passou. Conforme Biderman (2001), através da experiência sensorial com o mundo, o homem é capaz de organizar, 
classificar e categorizar os dados de sua experiência, e o faz através do léxico. Dessa forma, uma comunidade linguística difere de outra por conta dos aspectos políticos, econômicos, sociais e culturais experienciados durante seu percurso histórico. Esses aspectos são sentidos na língua por meio da variação linguística.

Há diversos tipos de variação, como a diastrática, relacionada à condição social do indivíduo; a diageracional, que se refere à sua faixa etária; a diagenérica, relativa ao gênero - masculino ou feminino; a diamésica, que diz respeito ao meio pelo qual a mensagem está sendo transmitida - oral ou escrito; a diafásica, vinculada à situação comunicativa - se mais formal ou mais informal. Além dessas, há a variação diatópica, central nos estudos dialetológicos, que realça a importância das vivências do falante quando em seu espaço geográfico, pois, conforme afirma Cardoso (2010, p. 15):

O espaço geográfico evidencia a particularidade de cada terra, exibindo a variedade que a língua assume de uma região para outra, como forma de responder à diversidade cultural, à natureza da formação demográfica da área, à própria base linguística preexistente e à interferência de outras línguas que se tenham feito presentes naquele espaço no curso de sua história.

Nesse sentido, o espaço geográfico possibilita a observação da leitura que uma comunidade realiza de seu contexto e a preservação de parte da sua memória sócio-histórica e linguístico-cultural, além de possibilitar a documentação da variação lexical e geolinguística da língua.

Conforme assinala Bagno (2007, p. 36), a língua é "intrinsecamente heterogênea, múltipla, variável, instável e está sempre em desconstrução e em reconstrução. [...] a língua é um processo, um fazer-se permanente e nunca concluído". O autor, ao falar do real estado da língua, chama a atenção para o fato de que a "nossa língua" não pode ser vista como um produto pronto e acabado: "a língua é uma atividade social, um trabalho coletivo, empreendido por todos os seus falantes, cada vez que eles se põem a interagir por meio da fala ou da escrita” (2007, p. 36).

Ainda segundo Bagno (2002, p. 179), 
... não existe um comportamento lingüístico homogêneo por parte dos 'falantes cultos', sobretudo (mas não somente) no tocante à língua falada, que apresenta variação de toda ordem segundo a faixa etária, a origem geográfica, a ocupação profissional etc. dos informantes.

Diante dessa realidade, dizer que a língua apresenta variação significa dizer que ela é heterogênea. A variação, portanto, ocorre em todos os níveis da língua: fonético-fonológico, morfológico, sintático, semântico, lexical, estilístico-pragmático (social). Sendo assim, ela deve ser vista por suas características: organizada, estruturada e condicionada por múltiplos fatores, isto é, a língua seria dotada de uma "heterogeneidade ordenada", na qual a variação é sistemática, obedecendo a regras, a motivações mais ou menos previsíveis, possibilitando que se façam algumas generalizações (LABOV; WEINREICH; HERZOG, 2006, p. 100).

Borba (1975, p. 134-135), ao explanar sobre o processo de nominação, apresenta a dupla função da linguagem - comunicação e expressividade como um fenômeno genuinamente cultural. Para este autor, a nominação se divide em intelectiva e expressiva. Na primeira,

... o objeto recebe um nome, seja porque não o tem ainda, seja porque o que tem não lhe assegura suficientemente a função. Ela descreve a coisa atentando para seus caracteres objetivos (forma, função, relações). [...] Esta associação pode ser de dois tipos: por semelhança (metáfora) e por contigüidade (metonímia e sinédoque). [...] [Já a expressiva] nomeia a coisa com relação ao falante e exprime o valor afetivo, desiderativo, estético, moral que este lhe atribui (BORBA, 1975, p. 134-135).

Assim, por meio da exegese das designações registradas para 'calvo', comprova-se de que modo análises geolinguísticas permitem a marcação de fenômenos linguísticos variáveis, muitas vezes não dicionarizados. Em suma, muitas ocorrências, nem sempre termos populares ou de amplitude geográfica - produto do cotidiano e da cosmovisão locais - são resgatadas por inquéritos dialetológicos. No caso específico de conceitos para 'calvo', são notórias a multiplicidade de vocábulos, bem como das causas e efeitos socialmente construídos quanto aos "que não possuem cabelo na cabeça" na Galícia e no Brasil. 


\section{Os Efeitos de Sentidos sobre Ser/Estar Calvo}

Ser ou estar careca sempre produziu significados sociais, com efeitos de sentido e ethos positivos ou negativos. Seja por genética, por questões de saúde ou por deliberada vontade dos indivíduos ou estética social, ser/estar calvo produz as mais variadas atitudes e sensações, que vão da vergonha juvenil à autoafirmação midiática, quase totalmente referente ao sexo masculino. A ausência de cabelo na mulher tende a ser vista de modo impactante, principalmente relacionada ao tratamento de um câncer. Historicamente, a calvície costumava remeter a pessoas velhas, fracas, doentes ou mesmo impotentes. Tais remissões não podem mais ser tomadas como únicas possibilidades para o estado de calvície, principalmente pela acepção positiva ou aceitável dada à ausência de cabelo na cabeça nas últimas décadas.

Um exemplo disso é o estudo de Mannes (2012), em que o autor demonstra a relação entre (a falta de) cabelos e a percepção da masculinidade. Em seu artigo "Shorn Scalps and Perceptions of Male Dominance" (Calvície completa e percepções da dominação masculina), sugere três análises sobre a calvície:

No primeiro estudo, os carecas foram classificados como mais dominantes que os cabeludos. No segundo, os cabelos dos participantes foram retirados digitalmente, e os que ficaram carecas foram classificados como mais dominantes, altos e fortes do que realmente eram. O terceiro estudo [...] demonstra que os homens que estão perdendo cabelo naturalmente melhoram sua relação com outras pessoas quando optam por raspar o cabelo completamente.

Enfim, os quadros sociais que destacam figuras com calvos demonstram as variadas imagens sociais nelas presentes, principalmente na sociedade ocidental contemporânea, onde ser calvo vem ganhando status de segurança e confiança, inclusive com a ascensão de símbolos sexuais carecas, algo impensável há décadas. 


\section{Língua Portuguesa e Língua Galega: raízes ibéricas}

Um estudo comparativo de cartas linguísticas em línguas e países diferentes pode, em uma primeira impressão, parecer insignificativo. No entanto, ao conhecer a história dos dois idiomas e dos territórios da Lusitânia e da Galícia, revela-se que o português e o galego foram, no período linguístico pós-romance, uma única língua. Assim, a questão da Galícia e sua relação com a língua portuguesa, ou o Brasil, pode ser tomada sob diversos prismas, como geolinguístico, histórico e identitário.

Tal relação entre galego e português, como não poderia deixar de ser, explica-se inicialmente pela contiguidade territorial entre a Galícia e Portugal no perímetro da Península Ibérica, divididos pelo Rio Minho desde 1297, pelo Tratado de Alcanizes.

Figura 1 - A Península Ibérica no século XXI

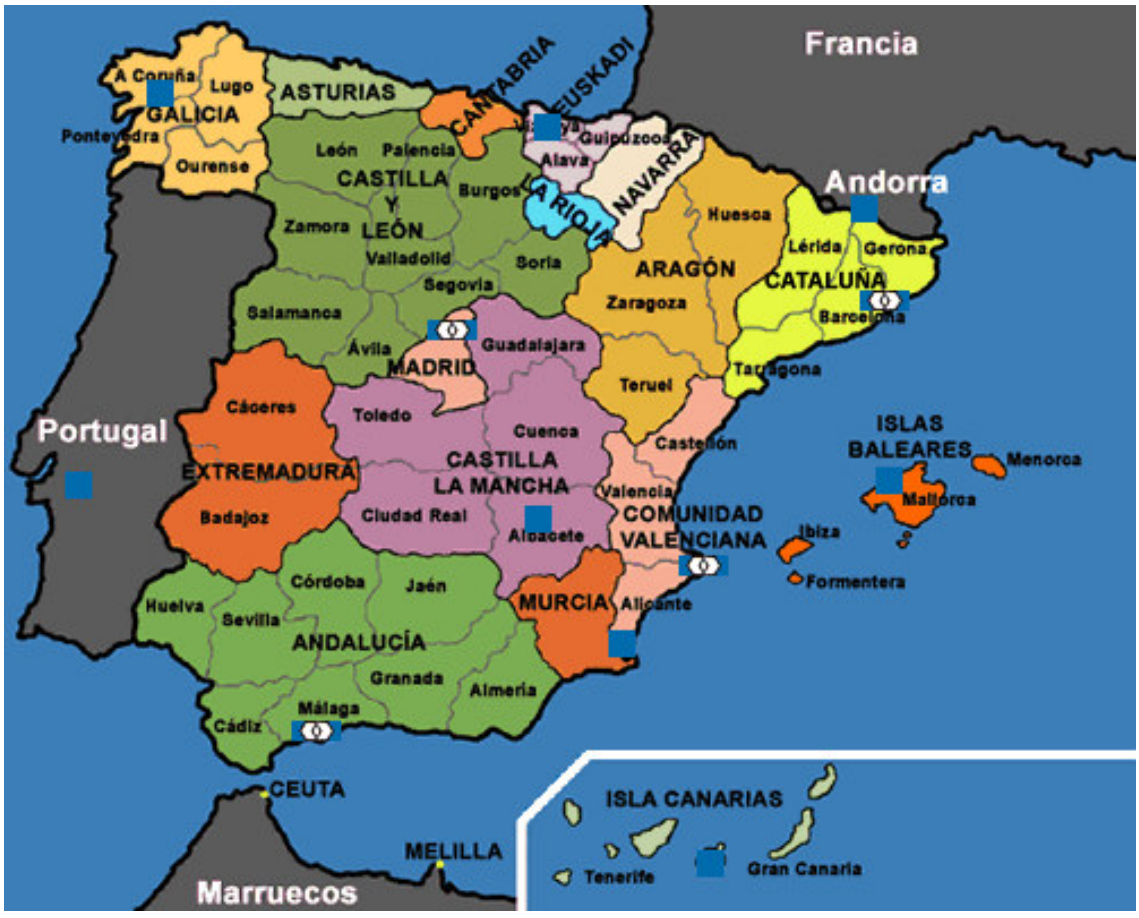

Fonte: Disponível em: <http://bit.do/cUNam>. 
Foi na Alta Idade Média, principalmente os séculos XII e XIII, que os últimos territórios da Península Ibérica foram retomados pelos reinos cristãos, em um processo bélico-religioso-cultural conhecido como Reconquista Cristã. Os povos finalmente subjugados foram os árabes, de origem africana e de fé islâmica, após quase sete séculos de coexistência na Ibéria, promovendo intercâmbios de toda ordem. Linguisticamente, a língua árabe foi tomada como superestrato da Língua Portuguesa, dado seus empréstimos, majoritariamente lexicais (TEYSSIER, 1997).

Assim, a partir da crescente expulsão dos árabes do território ibérico no sentido norte-sul, a língua da região Noroeste da península - galegoportuguês -, ainda única, foi se diferenciando dos demais falares românicos, como o catalão e o castelhano. Passou a tomar cada vez mais forma a partir de seus primeiros registros escritos, no fim do século XII.

Os estudos sobre a cronologia da língua portuguesa admitem historicamente uma fase galego-portuguesa, como é o caso do estudo de Pilar Vasquez Cuesta (apud MATTOS E SILVA, 2006, p. 25), que intitula o período dos primeiros documentos em língua portuguesa, por meio principalmente da lírica e do cancioneiro medieval português, de galegoportuguês, de 1214-1216 a meados dos anos Quinhentos, quando datam as primeiras gramáticas em português.

Quanto à identidade galega, sua vinculação junto ao Estado espanhol trouxe marcas à perpetuação e disseminação da língua, como afirma Rodríguez (1996), tendo de haver políticas linguísticas in vitro (CALVET, 2007) no âmbito dessa comunidade autônoma:

Durante vários séculos, o galego permaneceu apenas como língua oral porque a língua oficial era o castelhano. No século XIX houve um movimento para valorizar o galego e, desde então, passou a ser usado também como língua escrita. Depois da autonomia da Comunidade Autônoma da Galiza, a Constituição do Estado Espanhol permite o uso do galego como língua oficial, ao par do espanhol. Foi padronizado e agora tem largo uso na Galiza. O galego atual é a língua mais próxima ao português, porém, entre elas, há bastantes diferenças. Ainda existem discordâncias quanto ao futuro do galego. Alguns preferem que ele se integre o mais possível no português. Há 
quem procure outras soluções, mas a Xunta de Galicia adotou as Normas da padronização desde que foram publicadas, em 1982 (RODRÍGUEZ, 1996).

Politicamente, a posição oficial na Galícia é considerar o português e o galego como línguas autônomas, mesmo havendo tão pouca diversidade em todos os níveis linguísticos. No entanto, linguisticamente, e porque não igualmente no campo político, alguns linguistas têm uma visão bem restrita da filiação entre estas línguas. Bagno, por exemplo, em sua Gramática Pedagógica do Português Brasileiro (2012), advoga que o português brasileiro - na verdade, para ele apenas Brasileiro -, é oriundo do galego e pertence a um grupo linguístico chamado portugalego. Tal argumento advém do uso "de critérios de classificação das línguas que não correspondem ao que se faz tradicionalmente nos estudos de linguística histórica" (BAGNO, 2012, p. 201) ${ }^{1}$. Assim, sendo o Brasileiro um estágio posterior do galego, nesta visão, igualmente o galego e o português contemporâneos são parte de um mesmo sistema, com diferentes normas escritas, tal qual os casos do Brasil e de Portugal, ou entre os Estados Unidos e a Inglaterra.

Uma vez que o nível linguístico aqui cotejado é o lexical, crê-se como prudente notar até que ponto a intercompreensão nas duas línguas é possível. Como descrito, há teses que apontam para uma única língua enquanto outras as colocam lado a lado no ramo românico. Se ambas as línguas são próximas ou até mesmo fases de um mesmo idioma, a pergunta motivada por estes argumentos é "onde acaba/quando acabou o português e começa(ou) o galego?”.

Como afirma Coseriu (1973, p. 23, grifos do original), "no momento em que nos perguntamos por que uma língua é assim e não de outro modo, ou nos perguntamos que língua é esta, e respondemos de alguma maneira [...], já iniciamos uma narração e, como dizia Hermann Paul, fazemos história 'mesmo sem o saber"'. Daí, uma incursão à história dessas línguas explicita quais suas principais características lexicais.

${ }^{1}$ Para um maior conhecimento dessa tese, vide Bagno (2012, p. 201-253), no capítulo 5, Do galego ao brasileiro, a história de nossa lingua. Neste artigo, não se tomará este argumento, mas se pontuará a variante além da língua de Camões como Português Brasileiro (PB). 
O latim certamente é o ponto de convergência dessas línguas, por meio da romanização e do consequente processo de latinização da Ibéria, iniciado no século II a.C. As línguas autóctones, substratos no contato interétnico, deixaram um vocabulário mínimo, como na flora, na fauna, na toponímia e em utensílios primários, que demonstram, em um cotejo de seus campos onomasiológicos, a possibilidade de entendimento do modus vivendi dessas comunidades (TEYSSIER, 1997).

Os estudos dialetológicos no âmbito destes dois territórios - Galícia e Brasil -, também permitiram uma descrição detalhada. Uma das técnicas de se estudar a língua na perspectiva da Dialetologia é por meio dos atlas linguísticos, que são conjuntos de mapas, denominados cartas, onde ficam registradas todas as variações fonéticas, léxico-semânticas e morfossintáticas, presentes em cada uma das regiões, sub-regiões e localidades onde essas variações existem.

No que concerne à realidade brasileira, o estudo dos falares regionais tem suscitado o interesse de pesquisadores, de forma sistemática, pelo menos a partir do século XIX, quando aparecem os primeiros léxicos e glossários regionais a que se seguem trabalhos de natureza monográfica, iniciados com O Dialeto Caipira, contemplando os diversos níveis da língua, entre os quais o lexical. Tal interesse ganha mais notoriedade com trabalhos sobre áreas específicas, marcados, no seu início, pela publicação de três obras que se tornaram referência: O Dialeto Caipira, de Amadeu Amaral, em 1920; O linguajar carioca, de Antenor Nascentes, em 1922; e A lingua do Nordeste, de Mário Marroquim, em 1934 — e com a publicação de atlas regionais. O primeiro deles, o Atlas Prévio dos Falares Baianos (APFB), publicado em 1963, marca o início efetivo da Geolinguística brasileira. A análise dos atlas linguísticos bem como dos estudos geolinguísticos produzidos no Brasil nas últimas décadas denuncia o interesse crescente pelo enfoque do componente semântico-lexical por parte de muitas pesquisas que se dedicam à Geolinguística.

Em relação ao cenário galego, particularmente na área da Dialetologia e da Sociolinguística, muitos estudos vêm sendo realizados, trazendo contribuições para o conhecimento e difusão da língua galega. Segundo esclarece González, Novoa e Martínez (2006, p. 310), o Atlas Lingüístico Galego surgiu como um excelente instrumento para o estudo da fonética, da morfologia e da sintaxe galega, além de ter uma excelente contribuição para 
os estudos lexicais pelo fato de apresentar as cartas linguísticas ordenadas por campos semânticos, possibilitando o estudo das estruturas do vocabulário, tanto na formação de áreas lexicais como também na área da semântica funcional. Pode-se constatar que, apesar da grande influência exercida pela língua do Estado e da política de globalização atual, o galego vem despertando o interesse de estudiosos que pretendem pesquisar mais sobre essa língua.

Nos dois atlas cotejados neste artigo, que possuem períodos próximos de coleta de dados - década de 1960 na Bahia e de 1970 na Galícia -, percebe-se o esforço bem-sucedido dos autores na busca para retratar a variação lexical de cunho diatópico, que resulta na elaboração de cartogramas lexicais. Acrescenta-se a essa produção bastante expressiva um número relativamente grande de estudos geolinguísticos, artigos e capítulos de livro que têm buscado focalizar um dado item lexical, vários itens lexicais ou uma determinada área semântica. $\mathrm{O}$ mérito desses trabalhos reside em colocar em foco o componente semântico-lexical, tarefa que um atlas, por visar à descrição da totalidade dos dados coletados, não objetiva fazer.

\section{Os Atlas Linguísticos Pesquisados}

Nesta pesquisa, o grupo brasileiro em evidência foi estudado a partir dos dados do Atlas Prévio dos Falares Baianos (APFB), publicados no Atlas Lingüistico de Sergipe (ALS), por meio das cartas conjuntas Bahia-Sergipe, e do lado galego foi selecionado o Atlas Lingüístico Galego (ALGa).

No que diz respeito aos atlas brasileiros publicados, pode-se dizer que são pioneiros o APFB, da Bahia, de 1963, e o ALS, de Sergipe, que, por falta de financiamento, foi publicado somente em 1987, mas cuja coleta de dados remete aos anos de 1965 a 1967. No atlas sergipano, que se pretendia uma continuação do APFB, podem ser encontradas algumas cartas linguísticas conjuntas, trazendo lado a lado as realizações resgatadas em ambos os atlas, como é o caso da carta $n^{\circ} 80$, cotejada neste artigo (Anexo A). Trata-se dos casos em que os dados coletados não foram cartografados no APFB, mas foram resgatados posteriormente para serem publicados no ALS, aproveitando um caráter comparativo fornecido pelas cartas Bahia/Sergipe.

O Atlas Prévio dos Falares Baianos, coordenado por Nelson Rossi, foi o primeiro atlas linguístico produzido em terras brasileiras, feito e publicado 
entre 1960 e 1963. Recobre todo o estado da Bahia, com uma rede de 50 localidades, que se distribuem pelas diferentes áreas geográficas e culturais. A obra é constituída de dois volumes: o primeiro, compreendendo as cartas, em folhas soltas (ROSSI, 1963), e o segundo, encadernado, com introdução, questionário comentado e elenco das respostas transcritas (Rossi, 1965).

O APFB circunscreve-se ao estado da Bahia, que ocupa uma área de $564.733,177 \mathrm{~km}^{2}$, parte do falar baiano, segundo Nascentes (1953), que figura como área intermediária entre as duas grandes regiões linguísticas brasileiras por ele estabelecidas: a Região Norte e a Região Sul. Reúne dados coletados em meados do século XX, começos da década de 1960. Essa obra contempla diversos campos semânticos, tais como: agricultura; anatomia; fisiologia humana - onde se circunscrevem as denominações para 'calvo' -; culinária e alimentação; geografia; animais; vida social; astronomia; entre outros, e possui 209 cartas linguísticas que trazem transcrição, legendas ou símbolos, em preto e branco e coloridos.

Partindo de exaustiva análise em sondagens preliminares, elaborou-se um Extrato de Questionário com 182 perguntas (apesar de a numeração finalizar em 164, pois algumas dessas perguntas são subdivididas e indexadas com as letras A, B, C e D) e foram entrevistados dois sujeitos por ponto.

Mesmo com a intenção de inserir, em todas as localidades, informantes dos dois sexos e de idades diferentes, não foi possível atingir, de modo sistemático, a distribuição diassexual. É importante mencionar que o APFB pôs em evidência traços fonéticos, léxicos e semânticos de importante representatividade que foram coletados a partir dos inquéritos linguísticos com perguntas de formulação indireta, mas também em alguns casos com os testes de identificação para verificar a existência da forma em questão no vocabulário passivo do informante ou corrigir enganos na formulação da pergunta (esses casos estão com identificação com asterisco).

No âmbito europeu, o Atlas Lingüistico Galego (ALGa) constitui um conjunto de mapas linguísticos, de interesse morfológico (volumes $1 \mathrm{e}$ 2), fonético (volume 3) e lexical (volumes 4 e 5). O volume 5, que será tratado neste artigo e focaliza a área semântica "O ser humano", foi produzido pelos dialetólogos Rosario Álvarez Blanco; Francisco Dubert García e Xulio Sousa Fernández. O ALGa reúne dados coletados entre 1974 e 1977, por Rosario Álvarez Blanco, Francisco Fernández Rei e Manuel González 
González, que também participaram da elaboração do questionário com seus professores Constantino García e Antón Santamarina.

O ALGa possui uma rede de 167 localidades, correspondendo a uma área de $29.575 \mathrm{~km}^{2}$, (152 na Galícia e 15 no galego exterior). Em termos metodológicos, os dados normalmente eram coletados por um inquiridor, que fazia um inquérito em um ponto enquanto outros dois faziam, cada um, demais inquéritos em pontos próximos. No entanto, não houve uma divisão de âmbito linguístico em três zonas, pois também houve casos em que os três inquiridores fizeram a pesquisa em um mesmo ponto, com o intuito de discutir as formas conflitivas obtidas e garantir a homogeneidade de ouvido e transcrição.

Em cada inquérito do ALGa, se buscava um informante principal e outros secundários para preencher as lacunas, principalmente nos casos de léxico muito especializado (tear, ferramentas de alguma profissão). Também houve casos em que foi necessária a divisão do questionário entre dois informantes, pelo fato de um só não ter a disponibilidade de dois ou três dias necessários para responder ao questionário. O ALGa traz respostas de informantes dos dois sexos, embora existam mais homens, e de faixa etária intermediária e mais avançada (por volta dos 60 anos). No que diz respeito à escolaridade, foram entrevistados informantes com pouca escolaridade, mas com a chamada "inteligência natural", que conhecessem sobre agricultura, como os lavradores.

O questionário do volume 5 do ALGa é relacionado ao tema corpo humano (informação entre as perguntas 2065 e 2306), incorporando dados adicionais dos informantes, que não se limitaram a responder as perguntas concretas. Todas as respostas foram transcritas diretamente, além de gravadas em fitas magnetofônicas para possibilitar a constatação de amostras reais de comunidade de fala.

\section{As Cartas Linguísticas 80 do Atlas Lingüístico de Sergipe e 99 do Atlas Lingüístico Galego: descrição e análise dos dados}

A interpretação de cartas linguísticas expostas em diferentes atlas se configura como uma ação importante para os estudos dialetológicos, devido às possibilidades de inferências quanto ao modus vivendi e cogitandi em loci de 
pesquisa tão longínquos - Nordeste brasileiro e Ocidente europeu.

As cartas linguísticas $n^{\circ} 80$ do ALS e no 99 do ALGa apresentam os registros das variantes anotadas para o conceito 'calvo'. A primeira delas foi motivada pela pergunta: "Como se chama o homem que não tem cabelo na cabeça?”. As cartas conjuntas Bahia/Sergipe reúnem, em uma mesma folha, o cartograma da Bahia, à esquerda, e de Sergipe, à direita, e contempla as respostas documentadas na pesquisa de campo nestas duas áreas, como pode ser visto no Anexo A². $\mathrm{Na}$ Galícia, por sua vez, as respostas foram motivadas pela questão: "Como se chama a persoa que sufriu unha caída total ou parcial de pelo da cabeza?”. Sua verificação cartográfica pode ser mais bem observada na própria carta linguística, registrada no Anexo B.

A disposição espacial dos dados registrados (Quadro 1) destaca as denominações da Bahia e da Galícia.

Como pode ser visto no Quadro 1, ocorrem cinco variantes na Bahia e seis na Galícia para o conceito de 'calvo'. Três ocorrências baianas coincidem com as inscritas no território galego - calvo, careca e pelado -, sendo exclusivas as lexias coroado e cravista no território baiano e careco, carecas e pelacho no galego.

Chama a atenção, também, a frequência de ocorrência de cada um desses vocábulos nos inquéritos realizados, uma vez que careca se configurou como a denominação mais frequente na Bahia e calvo e pelado como o segundo e o terceiro vocábulos mais produtivos, respectivamente. A lexia coroado aparece em duas localidades baianas territorialmente distantes entre si (31 entre a Mesorregião Centro-Norte e a do Vale do São Francisco; 50 Extremo Sul). O termo registrado exclusivamente na Bahia, cravista, foi encontrado nos pontos 20 e 30 (Mesorregião do Centro-Norte baiano).

No caso do galego, calvo se configurou como o mais frequente na Galícia, pelado e careco como o segundo e o terceiro mais produtivos, respectivamente. A lexia pelacho aparece em uma localidade galega (C07 San Cristovo - Extremo Norte). O termo careca foi encontrado no ponto O22 (Campobecerros - Extremo Sul) e carecas na localidade O26 (Terrachá - Extremo Sul).

${ }^{2}$ É interessante mencionar que esta carta não existe no APFB, mas apenas no ALS, por fazer parte de um conjunto de cartas BA-SE (Cartas Bahia-Sergipe), que contemplam os dados da Bahia que não geraram cartas no APFB. 
Quadro 1 - Ocorrências lexicais na Bahia e na Galícia

\begin{tabular}{|c|c|c|c|}
\hline \multicolumn{2}{|c|}{ ALS (dados da Bahia) } & \multicolumn{2}{|r|}{ ALGa (dados da Galícia) } \\
\hline $\begin{array}{l}\text { Lexia por } \\
\text { ordem de } \\
\text { ocorrência }\end{array}$ & Ponto(s) de Inquérito & $\begin{array}{c}\text { Lexia por } \\
\text { ordem de } \\
\text { ocorrência }\end{array}$ & Ponto(s) de Inquérito \\
\hline 1. Careca & $\begin{array}{l}3,4,5,6,7,8,9,10,11,12, \\
13,14,15,16,17,18,19, \\
20,21,22,23,24,25,26, \\
29,31,32,33,34,35,36, \\
38,39,40,43,44,45,46, \\
47, \quad 48, \quad 49, \quad 50) \\
=42 \text { localidades }\end{array}$ & 1. Calvo & $\begin{array}{l}\text { (A01, A02, A03, A04, A05, A06, A07, } \\
\text { C03, C04, C05, C06, C07, C08, C09, } \\
\text { C10, C11, C13, C15, C18, C19, C20, } \\
\text { C21, C22, C24, C26, C30, C31, C33, } \\
\text { C34, C36, C37, C38, C39, C40, C41, } \\
\text { C42, C43, C44, C45, C46, C47, C48, } \\
\text { C49, L01, L02, L03, L04, L06, L07, } \\
\text { L08, L09, L10, L11, L12, L13, L14, } \\
\text { L15, L16, L17, L18, L20, L22, L23, } \\
\text { L24, L25, L26, L27, L28, L30, L32, } \\
\text { L33, L34, L35, L36, L37, L38, L39, } \\
\text { LE01, LE02, LE03, LE04, LE05, } \\
\text { O01, O02, O03, O04, O05, O06, } \\
\text { O07, O08, O09, O10, O11, O12, } \\
\text { O13, O14, O15, O16, O17, O18, } \\
\text { O19, O20, O21, O22, O23, O25, } \\
\text { O27, O28, O29, O30, P01, P02, P03, } \\
\text { P04, P05, P06, P07, P08, P09, P10, } \\
\text { P11, P12, P13, P14, P15, P16, P17, } \\
\text { P18, P19, P20, P21, P22, P23, P24, } \\
\text { P25, P26,P27, P28, P31, P32, Z01, } \\
\text { Z03) = 142 localidades }\end{array}$ \\
\hline 2. Calvo & $\begin{array}{l}(2,3,4,5,7,8,9,11,15,16, \\
19,20,22,23,26,27,30, \\
31,32,33,34,37,38,39, \\
41, \quad 42, \quad 43, \\
=28 \text { localidades }\end{array}$ & 2. Pelado & $\begin{array}{l}\text { (A05, C01, C02, C03, C05, C09, C10, } \\
\text { C11, C12, C13, C14, C15, C16, C17, } \\
\text { C19, C21, C23, C25, C26, C27, C28, } \\
\text { C29, C32, C33, C35, C36, C38, C39, } \\
\text { C41, C42, C43, L02, L03, L05, L09, } \\
\text { L10, L11, L16, L17, L18, L19, L20, } \\
\text { L21, L24, L27, L29, L31, L35, L36, } \\
\text { L37, LE01, LE03, LE04, O01, O02, } \\
\text { O03, O04, O05, O06, O07, O11, } \\
\text { O13, O14, O16, O19, O20, O22, } \\
\text { O24, O26, O27, O28, O29, O31, P02, } \\
\text { P03, P07, P09, P11, P19, P20, P25, } \\
\begin{array}{l}\text { P27, P32, P33, Z02) } \\
=85 \text { localidades }\end{array}\end{array}$ \\
\hline 3. Pelado & $\begin{array}{l}(7,9,10,11,12,13,34,37, \\
42)=9 \text { localidades }\end{array}$ & 3. Careco & $\begin{array}{l}\text { (P19, P22, P29, P30, P32) } \\
=5 \text { localidades }\end{array}$ \\
\hline 4. Coroado & $(31,50)=2$ localidades & 4. Pelacho & $(\mathrm{C} 07)=1$ localidade \\
\hline 5. Cravista & $(20,30)=2$ localidades & 5. Careca & $(\mathrm{O} 22)=1$ localidade \\
\hline- & - & 6. Carecas & $(\mathrm{O} 26)=1$ localidade \\
\hline
\end{tabular}

Fonte: Elaboração própria 
Ao realizar uma análise comparativa dos dados, por meio do cotejamento de ocorrências linguísticas na Bahia e na Galícia, é possível verificar que a denominação careca é muito produtiva na Bahia e rara, com apenas uma ocorrência registrada, na Galícia. A forma pelado, que na língua portuguesa designa sem pelo algum, ocorre pouco na Bahia, mas se apresenta de forma bem produtiva nos dados do ALGa para se referir a careca.

\section{Análise das Ocorrências Lexicais}

A importância da Dialetologia para o conhecimento da Língua Portuguesa se dá não só pela identificação de fenômenos variáveis, mas também pelo confronto presença/ausência destes fenômenos em diferentes áreas por meio de pesquisas de campo.

A presença da carta ‘calvo' no ALS e no ALGa demonstra por si mesma a variação lexical na Bahia e na Galícia para o conceito 'aquele sem cabelo na cabeça'. Partindo das ocorrências inscritas nas referidas cartas linguísticas, analisaram-se as motivações para a denominação desses vocábulos, considerando sua etimologia. No Quadro 2, expõe-se o que Saraiva (1993) apresenta em seu dicionário de língua latina, disposto nas colunas Origem do radical e significado. No campo Motivação, os autores deste artigo demonstram sua(s) hipótese(s) para a motivação referente a cada lexia quanto à ausência de cabelo na cabeça.

Os dados expostos, como já era esperado por meio de hipóteses iniciais antes da análise das cartas linguísticas, atestam que o latim é o terminus a quo não apenas para as lexias coletadas, mas também do tesouro vocabular e dos processos neológicos em ambos os idiomas - português e galego. Por se configurarem línguas românicas e por suas origens sócio-históricas entrelaçadas, a hipótese de existência de lexias homógrafas ou homônimas foi comprovada pelas cartas confrontadas.

Também interessou a este artigo entender quantos e de que modo estavam dicionarizadas as lexias inscritas nas cartas analisadas. 
Quadro 2 - Variantes de 'calvo' na Bahia e na Galícia: etimologia

\begin{tabular}{|c|c|c|c|}
\hline Lexia & $\begin{array}{l}\text { Procedência } \\
\text { Linguística e } \\
\text { Lexia } \\
\text { Formadora }\end{array}$ & Significado & Possível Motivação \\
\hline 1) Calvo & $\begin{array}{l}\text { Latim } \\
\text { Calvus, a, um }\end{array}$ & $\begin{array}{l}\text { Calvo, liso, } \\
\text { desprovido }\end{array}$ & $\begin{array}{l}\text { Característica não rugosa da } \\
\text { superfície (ou) ausência de }\end{array}$ \\
\hline 2) Careca & $\begin{array}{c}\text { Latim } \\
\text { v. careo, es, ère, ui }\end{array}$ & $\begin{array}{l}\text { Ter falta de } \\
\text { alguma coisa, } \\
\text { abster-se }\end{array}$ & Ausência de, carência de \\
\hline 3) Cravista & $\begin{array}{l}\text { Latim } \\
\text { m. clavus, } i\end{array}$ & $\begin{array}{l}\text { Prego, cravo, } \\
\text { franja de púrpura }\end{array}$ & $\begin{array}{l}\text { Motivação fonética: calvo } \sim \\
\text { carvo } \sim \text { cravo } \sim \text { cravista }\end{array}$ \\
\hline 4) Coroado & $\begin{array}{l}\text { Latim } \\
\text { Part. pass. do } \\
\text { verbo Coronare }\end{array}$ & Coroa $(r)$, cingir & $\begin{array}{l}\text { Aparência de coroa na } \\
\text { cabeça, o que pode remeter à } \\
\text { imagem de uma pessoa calva }\end{array}$ \\
\hline 5) Pelado & $\begin{array}{l}\text { Latim } \\
\text { Pellatus part. } \\
\text { pass. do verbo } \\
\text { pellare }\end{array}$ & $\begin{array}{l}\text { Ato de pelar, de } \\
\text { retirar os cabelos } \\
\text { ou a barba }\end{array}$ & $\begin{array}{c}\text { Sem cabelo na cabeça } \\
\text { (sincronia: sem roupa / } \\
\text { partes do corpo sem cabelo) }\end{array}$ \\
\hline
\end{tabular}

Fonte: Elaboração própria

Hoje, é necessário repensar a questão da dicionarização de palavras, pois nem tudo que é falado constará nos dicionários de língua. No entanto, ainda se percebe o pouco diálogo existente entre os dicionaristas e os dados geolinguísticos, pois muitos itens lexicais ainda têm sua entrada ignorada nos dicionários de língua, embora sejam uma variante bastante produtiva. Conforme Biderman (2004, p. 185):

O dicionário é o depositário do acervo lexical da cultura. E como diz Alan Rey no prefácio do Petit Robert: o dicionário é a memória lexical de uma sociedade; constitui o acervo e o registro das significações 
que nossa memória não é capaz de memorizar. Convém lembrar ainda que o dicionário descreve o léxico em função de um modelo ideal de língua - a língua culta e escrita; pode, porém, registrar usos dialetais, populares, giriáticos esporadicamente. Por conseguinte, o dicionário convalida e promove a linguagem aceita e valorizada em sua comunidade.

No entanto, atualmente, já existem pesquisadores da área do léxico interessados em aproveitar os dados coletados pelas pesquisas de cunho dialetal para suprir e preencher as lacunas deixadas pelos dicionários convencionais e, assim, também, construir obras especificamente dialetológicas, ou seja, obras com os itens lexicais coletados in loco, baseados em dados da língua na modalidade oral. Conforme Aguilera (2011), tem-se, como exemplos, dois projetos internacionais de grande importância, a saber:

i) O Dicionário Dialetal Brasileiro (DDB), associado ao Atlas Linguístico do Brasil e coordenado pelo Dr. Américo Venâncio Lopes Machado Filho, em desenvolvimento na UFBA em cooperação com a Universidade Paris XIII. ii) Tesouro do léxico patrimonial galego e português, sediado no Instituto de Língua Galega, da Universidade de Santiago de Compostela (Espanha), tem como coordenadora geral a Dra Rosário Álvarez, dessa universidade e conta com três comitês: o galego, coordenado por Álvarez; o português, pelo Dr. João das Pedras Saramago, da Universidade de Lisboa e o brasileiro, pelas Dr ${ }^{\text {as }}$ Sílvia Figueiredo Brandão, da Universidade Federal do Rio de Janeiro e Vanderci de Andrade Aguilera, da Universidade Estadual de Londrina (AGUILERA, 2011, p. 272-273, grifos do original).

Assim, enquanto os dicionários citados por Aguilera (2011) ainda não forem lançados, a sociedade aguarda a recuperação dos dados dialetais e um melhor aproveitamento deles. O léxico de uma língua, em hipótese alguma, pode ser reduzido e/ou diminuído a um simples dicionário. Destaca-se a importância do dicionário, mas ele não é o único instrumento para guardar os itens lexicais de uma língua. Conforme cita Aguilera (2011, p. 277): 
Os registros dos atlas têm, dessa forma, uma contribuição relevante, considerando-se o expressivo volume de lexias ainda não acolhidas pelos dicionários em circulação. Assim sendo, os dicionários de língua portuguesa, ao incluírem dados dialetais, estarão prestando um serviço tanto à Dialetologia/Geolinguística como à Lexicografia, pela possibilidade de os interessados terem, além dos atlas, outro veículo de preservação de dados orais, mais popularizado e de mais fácil consulta pelo leitor leigo em Geolinguística.

Dessa forma, espera-se que o diálogo entre a Lexicografia e a Dialetologia/Geolinguística permaneça de forma harmoniosa e que venha render vários frutos, traduzidos em muitos dicionários com dados dialetais. Nessa perspectiva, com o intuito de observar a dicionarização das variantes coletadas, recorreu-se à pesquisa em dicionários. Deste intento, os Quadros 3 e 4 tratam de aspectos lexicográficos das lexias apresentadas nas cartas, destacando acepções e a presença/ausência deles nas obras consultadas. Para tal, considerou-se importante a investigação desses aspectos no dicionário histórico de Bluteau (1728) e em Moraes Silva (1789), por demarcarem um estado pretérito para essas lexias - até o século XVIII. Além destes, considerou-se verificar a presença dos vocábulos no português brasileiro contemporâneo, o que foi feito por meio do Dicionário Honaiss, em sua versão digital. Tal versão foi preferida uma vez que, tendo atualizações mais constantes, poderia apresentar conteúdo mais aprofundado. Também outros dicionários on-line da língua portuguesa foram investigados quando necessário, como foi o caso da lexia 'cravista', que não se encontra nas obras setecentistas e se apresenta com um significado diverso no dicionário contemporâneo cotejado.

No que concerne ao galego, foi consultado o Dicionário da Real Academia Galega (1913-1928), Diccionario gallego-castellano, onde se verificou a dicionarização de calvo e pelado apenas, e o Diccionario enciclopédico gallego-castellano, de Eladio Rodríguez González (1958-1961), onde foram encontradas as denominações calvo, careca, coroado e pelado dicionarizadas. 
Quadro 3 - Dicionarização das denominações

\begin{tabular}{|c|c|c|c|c|c|}
\hline $\begin{array}{c}\text { Lexia / } \\
\text { Dicionário }\end{array}$ & $\begin{array}{c}\text { Bluteau } \\
\text { (1728) }\end{array}$ & $\begin{array}{c}\text { Moraes Silva } \\
\text { (1789) }\end{array}$ & $\begin{array}{c}\text { Houaiss } \\
\text { on-line (s/d) }\end{array}$ & $\begin{array}{c}\text { DRA } \\
(1913-1928)\end{array}$ & $\begin{array}{c}\text { Eladio } \\
(1958-1961)\end{array}$ \\
\hline Calvo & $\begin{array}{l}\text { Aquelle, que tem } \\
\text { a cabeça, ou } \\
\text { parte dela sem } \\
\text { cabellos (p. } 65 \text { ) }\end{array}$ & $\begin{array}{l}\text { CALVA, s.f. falta } \\
\text { de cabellos } \\
\text { cahidos (p. 219) }\end{array}$ & $\begin{array}{c}\text { adj. e s.m. Diz-se } \\
\text { daquele cuja } \\
\text { cabeça é } \\
\text { completa ou } \\
\text { quase } \\
\text { completamente } \\
\text { desprovida de } \\
\text { cabelos; careca. } \\
\text { Que não tem } \\
\text { qualquer } \\
\text { vegetação, } \\
\text { descalvado: } \\
\text { monte calvo. }\end{array}$ & $\begin{array}{l}\text { s.m, s.f e adj. El } \\
\text { que tiene la } \\
\text { cabeza } \\
\text { desprovista de } \\
\text { cabellos. }\end{array}$ & $\begin{array}{l}\text { s. e adj. Que ha } \\
\text { perdido el pelo } \\
\text { de la cabeza, que } \\
\text { tiene la parte } \\
\text { superior de la } \\
\text { cabeza } \\
\text { desprovista de } \\
\text { pelo. }\end{array}$ \\
\hline Careca & $\begin{array}{l}\text { CARECER: ter } \\
\text { falta (p. 147) }\end{array}$ & $\begin{array}{l}\text { CARECER v. } \\
\text { haver mister, ter } \\
\text { necessidade } \\
\text { de alguma } \\
\text { pessoa, ou coisa, } \$ \\
\text { Não ter } v . g . \\
\text { carece de vício } \\
\text { (p. 234) }\end{array}$ & \begin{tabular}{|c|} 
adj. s. m. e f. Que \\
ou o/a que não \\
tem cabelos. \\
Calva, calvície; \\
alopecia, \\
falacrose.
\end{tabular} & - & $\begin{array}{c}\text { Vaina de las } \\
\text { habas y guisantes. }\end{array}$ \\
\hline Cravista & - & - & $\begin{array}{l}\text { m. e f. Pessôa } \\
\text { que toca cravo. }\end{array}$ & - & - \\
\hline Coroado & $\begin{array}{c}\text { COROA, o alto } \\
\text { da } \\
\text { Cabeça: "dava a } \\
\text { agua a huns pelas } \\
\text { barbas, a } \\
\text { Outros pelas } \\
\text { coroas" Náutico. } \\
\text { (p. 331) } \\
\text { COROAR n. } \\
\text { Começar a } \\
\text { apparecer no } \\
\text { nacedouro a } \\
\text { cabeça da } \\
\text { criança. (p. 332) }\end{array}$ & $\begin{array}{l}\text { Que tem coroa } \\
\text { (p. } 473)\end{array}$ & $\begin{array}{c}\text { adj. Que tem } \\
\text { coroa. } \\
\text { Que tem } \\
\text { dignidade } \\
\text { soberana: testa } \\
\text { coroada. } \\
\text { Fig. Premiado: } \\
\text { obra coroada pela } \\
\text { Academia. }\end{array}$ & - & $\begin{array}{l}\text { adj. coronado, } \\
\text { que tiene corona. }\end{array}$ \\
\hline Pelado & $\begin{array}{l}\text { PELLADO, part. } \\
\text { pass. de pellar. } \\
\text { §Terra- - } \\
\text { calva, sem } \\
\text { árvores, nem } \\
\text { plantas. }\end{array}$ & $\begin{array}{l}\text { Pellado. Terra } \\
\text { pelada; calva, sem } \\
\text { árvores, nem } \\
\text { plantas. (p. } 423 \text { ) }\end{array}$ & $\begin{array}{c}\text { adj. Sem pêlos, } \\
\text { ou penas. } \\
\text { Glabro; calvo. } \\
\text { A que tiraram a } \\
\text { pele. } \\
\text { Fig. Nu, despido. } \\
\text { Fig. Pobre, sem } \\
\text { dinheiro. }\end{array}$ & $\begin{array}{l}\text { adj. Pelado, que } \\
\text { ha perdido el } \\
\text { pelo o lo tiene } \\
\text { cortado a cercén: } \\
\text { cacha pelada. }\end{array}$ & $\begin{array}{l}\text { adj. Pelado, que } \\
\text { ha perdido el } \\
\text { pelo o lo tiene } \\
\text { cortado a cercén: } \\
\text { cacha pelada. }\end{array}$ \\
\hline
\end{tabular}

Fonte: Elaboração própria 
Do Quadro 3 conclui-se que nem sempre a lexia registrada nos atlas apresenta um significado referente a calvo. Foi o caso de careca e de pelado em Bluteau (1729) e Moraes Silva (1789), o que demonstra um processo de ressemantização, e de 'cravista' nos dicionários contemporâneos de língua portuguesa, que remete exclusivamente ao tocador do instrumento musical cravo $^{3}$. Calvo demonstra uma pluralidade semântica, uma vez que também remete à ausência de vegetação.

A seguir, a partir do Quadro 4, produziu-se uma síntese com referência à ausência de cabelo, legendada acerca da presença e semantização do corpus das cartas 80 do ALS e 99 do ALGa.

Quadro 4 - Variantes para 'calvo’: presença/ausência nos dicionários

\begin{tabular}{|c|c|c|c|c|c|c|}
\hline $\begin{array}{c}\text { Lexia / } \\
\text { Dicionário }\end{array}$ & $\begin{array}{c}\text { Bluteau } \\
\mathbf{( 1 7 2 8 )}\end{array}$ & $\begin{array}{c}\text { Moraes } \\
\text { Silva } \\
\mathbf{( 1 7 8 9 )}\end{array}$ & $\begin{array}{c}\text { Houaiss } \\
\text { on-line } \\
\text { (s/d) }\end{array}$ & Outros & $\begin{array}{c}\text { DRA } \\
\mathbf{( 1 9 1 3 -} \\
\mathbf{1 9 2 8})\end{array}$ & $\begin{array}{c}\text { Eladio } \\
\mathbf{( 1 9 5 8 -} \\
\mathbf{1 9 6 1 )}\end{array}$ \\
\hline Calvo & D & D & D & D & D & D \\
\hline Careca & DOS & DOS & D & D & ND & DOS \\
\hline Cravista & ND & ND & DOS & DOS & ND & ND \\
\hline Coroado & DOS & DOS & DOS & DOS & ND & DOS \\
\hline Pelado & DOS & DOS & D & DOS & D & D \\
\hline
\end{tabular}

Fonte: Elaboração própria

Legenda: D - Dicionarizado; ND - Não dicionarizado; DOS - Dicionarizado com outro significado

\section{Conclusões}

Diante dos dados analisados, é possível perceber a origem românica dos idiomas e a existência de variantes lexicais comuns nos mapas comparados

\footnotetext{
3 O Dicionário Informal, cuja versão é exclusivamente online, traz a seguinte acepção para cravista: "Mús. Pessoa que toca cravo ou compõe para esse instrumento". Disponível em: <http://bit.do/cUMPs>. Acesso em: 05 dez. 2014.
} 
dos dois atlas, bem como a ocorrência das designações calvo, careca e pelado na Galícia e na Bahia.

É possível verificar, também, variedades na Galícia para o conceito, pela constatação das denominações calvo (em 142 pontos), pelado (em 84 pontos), pelacho (em 5 pontos), careco (em 1 ponto), careca (em 1 ponto) e carecas (em 1 ponto). Na comparação dos dados, a denominação careca é muito produtiva na Bahia e rara, com apenas uma ocorrência, registrada na Galícia. A forma pelado, que na língua portuguesa designa sem pelo algum, ocorre pouco na Bahia, mas se apresenta de forma bem produtiva nos dados do ALGa para se referir a careca.

Assim, após analisar as cartas linguísticas com as denominações para calvo, presentes no ALS e no ALGa, pode-se concluir que a Dialetologia propicia um retrato linguístico de um determinado espaço físico e social. Dessa forma, uma análise dialetológica permite, dentre outras ações: (i) inventário das realizações linguísticas ativas e em mudança; (ii) perpetuação de um tesouro vocabular pelo registro de formas não dicionarizadas, documentando uma história linguística; (iii) melhor caracterização da dialetização, aqui explicitado pelo cotejamento de ocorrências linguísticas na Bahia e na Galícia, principalmente de caráter eminentemente oral; (iv) por fim, mas não por último, uma ação de política linguística e escolar que forneça a leigos, estudiosos e educadores orientações acerca da língua em diversos níveis linguísticos.

Nesse sentido, por agora, mostrou-se uma identidade lexical entre as línguas que os atlas estudados podem revelar. Espera-se, a partir do corpus de outros atlas, pesquisar o item semântico-lexical calvo nas demais áreas brasileiras e europeias para prosseguir nos estudos comparativos entre línguas românicas. 


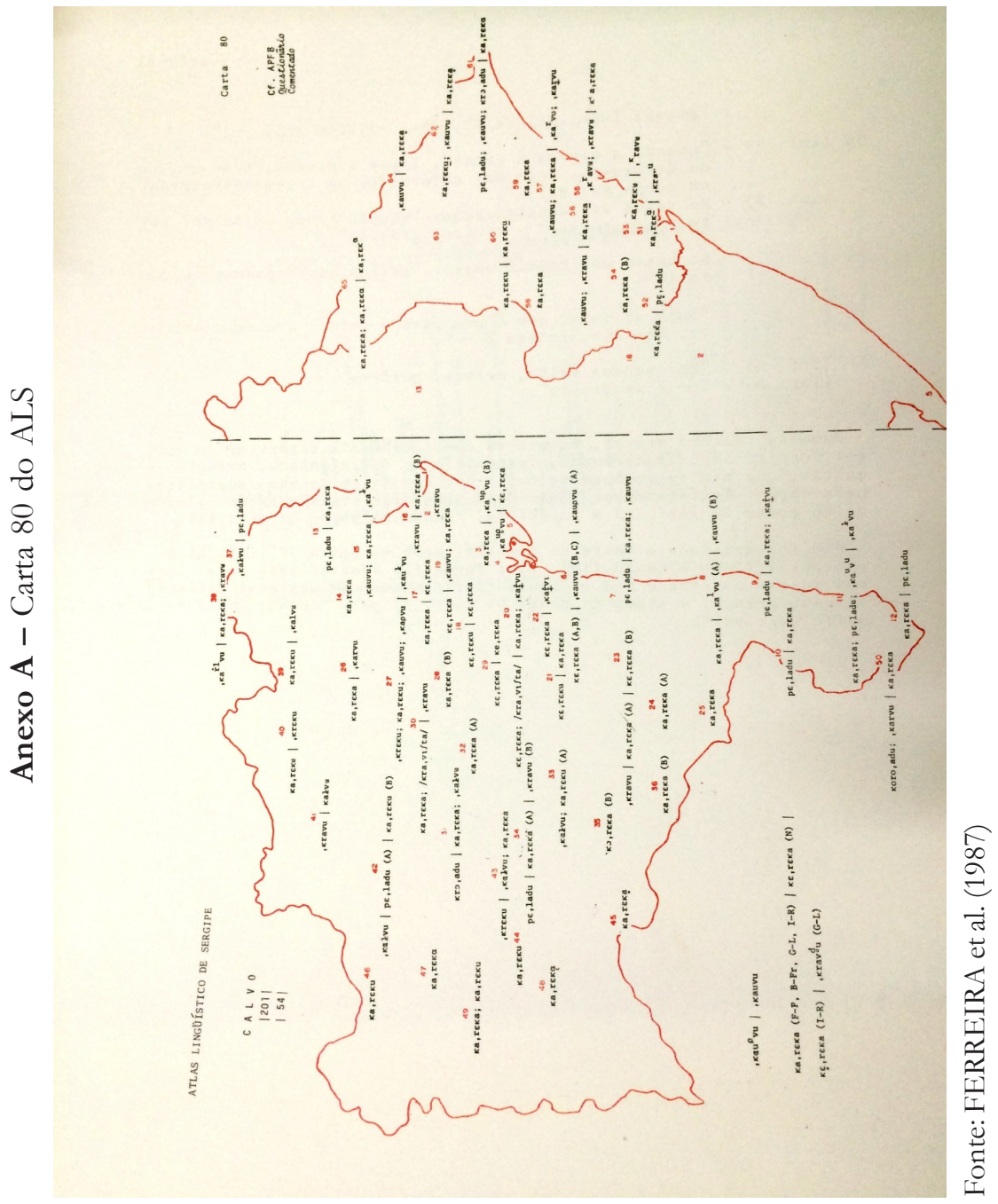




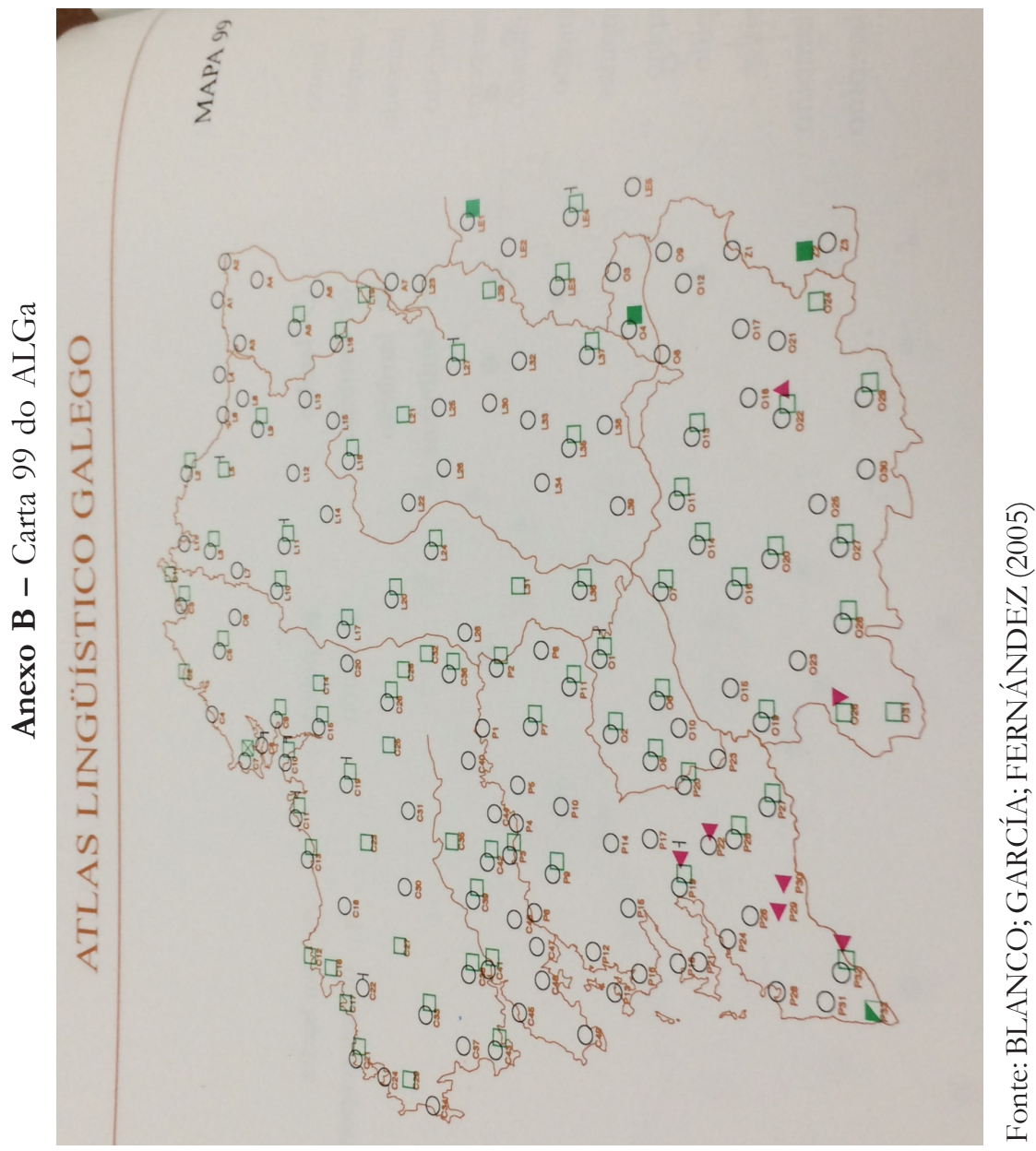




\section{Referências}

AGUILERA, V. de A. A importância dos dados geolinguísticos para construção de dicionários de Língua Portuguesa. In: CARDOSO, S.; MEJRI, S.; MOTA, J. (Org.). Os dicionários: fontes, métodos e novas tecnologias. Salvador: Vento Leste, 2011. p. 271-288.

AMARAL, A. O dialeto caipira. 2. ed. São Paulo: HUICITEC; Secretaria da Cultura, 1976 [1920].

BAGNO, M. Lingüistica da norma. São Paulo: Parábola, 2002.

BAGNO, M. Nada na língua é por acaso. São Paulo: Parábola, 2007.

BAGNO, M. Gramática pedagógica da língua portuguesa. São Paulo: Parábola, 2012.

BIDERMAN, M. T. C. Teoria Lingüística: teoria lexical e lingüística computacional. São Paulo: Martins Fonte, 2001.

BIDERMAN, M. T. C. Análise de dois dicionários gerais do português: o Aurélio e o Houaiss. In: ISQUERDO, A. N.; KRIEGER, M. G. (Org.). As ciências do léxico: lexicologia, lexicografia e terminologia. v. 2. Campo

Grande: Universidade Federal do Mato Grosso do Sul, 2004. p. 185-200.

BLANCO, R. A.; GARCÍA, F. D.; FERNÁNDEZ, X. S. Atlas Lingüístico Galego. v. 5. Léxico. O ser humano. A Coruña: Fundación Pedro Barrié de la Maza, 2005.

BLUTEAU, R. Vocabulario Portuguez e Latino. v. 1-4, Coimbra, Colégio das Artes, 1712-1713; v. 5-8, Lisboa, Pascoal da Sylva, 1716-1721, Suplemento ao Vocabulario Portuguez e Latino, 2v.; Lisboa, Joseph Antonio da Sylva, 1727, Patriarcal Officina da Musica, 1728.

BORBA, F. da S. Introducão aos estudos lingüísticos. 4. ed. São Paulo: Nacional, 1975.

CALVET, L.-J. As políticas lingüisticas. Florianópolis. São Paulo: Ipol;

Parábola, 2007. 
CARDOSO, S. A. M. Geolinguística: tradição e modernidade. São Paulo: Parábola, 2010.

COSERIU, E. Sistema, norma y habla. Madrid: Gredos, 1973.

FERREIRA, C. et al. Atlas Lingüistico de Sergipe (ALS). Salvador:

Universidade Federal da Bahia; Fundação Estadual de Cultura de Sergipe, 1987.

GONZÁLEZ, M. G.; NOVOA, K. V.; MARTÍNEZ, M. V. Dialectoloxía e xeografía humana. In: ÁLVAREZ, R.; GARCÍA, F. D.; FERNANDEZ, X. S. (Org.). Lingua e território. Santiago de Compostela: Conselho da Cultura Galega; Instituto da Língua Galega, 2006. p. 309-355.

GONZÁLEZ, E. R. Diccionario enciclopédico gallego-castellano., Vigo: Galaxia, 1958-1961. Disponível em: <http://bit.do/cUPVb>. Acesso em: 07 abr. 2015.

HOUAISS, A. Dicionário da Lingua Portuguesa. Versão on-line. Disponível em: <http://bit.do/cUPVx>. Acessado em: 27 dez. 2014.

LABOV, W; WEINREICH, U; HERZOG, M. Fundamentos empiricos para uma teoria da mudança lingüistica. São Paulo: Parábola, 2006.

MANNES, A. E. Shorn scalps and perceptions of male dominance. Social Psychological and Personality Science, v. 0, n. 0, p. 1-8, 2012. Disponível em: <http://bit.do/cUPWN>. Acesso em: 29 maio 2015 .

MARroqUIM, M. A língua do Nordeste: Alagoas e Pernambuco. 3. ed. Curitiba: HD Livros, 1996 [1934].

MATTOS E SILVA, R. M. Português arcaico. São Paulo: Contexto, 2006.

MORAES SILVA, A. Diccionario da Lingua Portugueza. v. 1 e 2. Lisboa: Typographia Lacérdina, 1813. (Edição brasileira pela Livraria Francisco Alves, 1922).

NASCENTES, A. O linguajar carioca. 2. ed. Rio de Janeiro: Organização Simões, 1953. 
REAL ACADEMIA GALEGA. Diccionario gallego-castellano. 1913-1928. Disponível em: <http://bit.do/cUPWT>. Acesso em: 12 abr. 2015.

RODRÍGUEZ, A. M. Galego e português modernos: um estudo comparativo. Revista Philologus, Rio de Janeiro, v. 6, p. 30-37, 1996. Disponível em: < http://bit.do/cUPWX>. Acesso em: 26 maio 2015.

ROSSI, N. Atlas Prévio dos Falares Baianos (APFB). Rio de Janeiro: Ministério de Educação e Cultura; Instituto Nacional do Livro, 1963.

ROSSI, N. Atlas Prévio dos Falares Baianos. Introdução. Questionário Comentado. Elenco das respostas transcritas. Rio de Janeiro: Ministério de Educação e Cultura; Instituto Nacional do Livro, 1965.

SARAIVA, F. R. dos S. Dicionário latino-português. Rio de Janeiro: Garnier, 1993.

TEYSSIER, Paul. História da língua portuguesa. São Paulo: Martins Fontes, 1997.

Recebido em: 27/05/2015 Aceito: 20/09/2015 